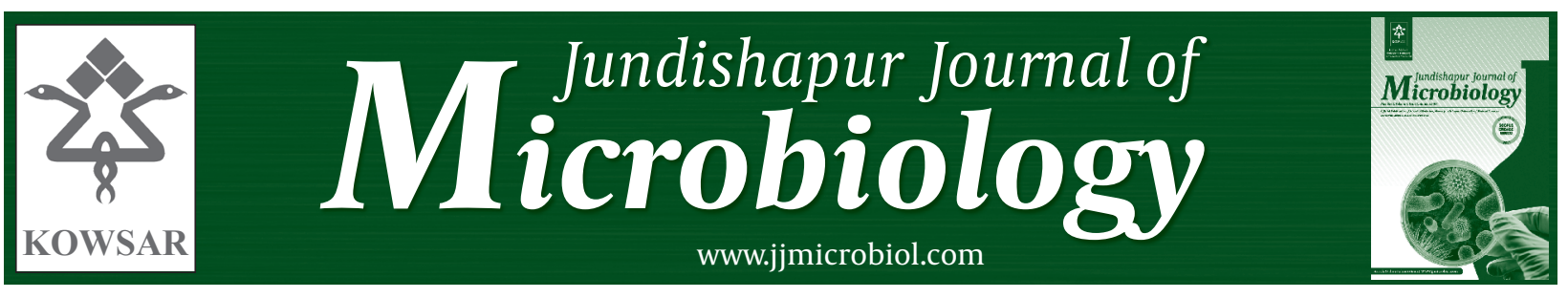

\title{
Isolation and Detection of Yeast Biofilms From Urine Catheters of Infectious Patients
}

\author{
Parisa Mohammadi ${ }^{1 *}$, Nahid Shoaie ${ }^{1}$, Shahla Roudbar Mohammadi ${ }^{2}$ \\ ${ }^{1}$ Department of Biology, Faculty of Science, Alzahra University, Tehran, IR Iran \\ ${ }^{2}$ Department of Mycology, Tarbiat Modares University of Medical Science, Tehran, IR Iran
}

A R T I C L E I N F O

Article type:

Original Article

Article history:

Received: 08 Oct 2011

Revised: 01 Jan 2012

Accepted: 22 Feb 2012

Keywords:

Yeasts

Candida glabrata

Candida tropicalis

Candida albicans

Candida Krusei

\begin{abstract}
A B S T R A C T
Background: Recent evidences have revealed that in more than $65 \%$ of microbial infections, biofilms have critical roles. The ability of yeasts to form biofilms on surface of medical devices such as urine catheters is an important reason of the capability of these microorganisms to cause human disease.

Objectives: The aim of this study was to isolate and identify yeasts on the surfaces of urine catheters and to investigate their ability to form biofilms.

Patients and Methods: In this research, 55 urine catheters from patients of ICU award of Army Family Hospital in Tehran (Iran) were assayed. The catheters were taken aseptically to the laboratory for studying biofilms. Then they were sonicated and cultured on Sabouraud dextrose agar, CHROM agar and Corn meal agar. Examination of germ tube, sugar absorption and PCR method by two primers of ITS1 and ITS4 were used to identify pathogenic yeasts.

Results: According to the classical methods and molecular techniques, Candida albicans, C. krusei, C. glabrata and C. tropicalis were identified.

Conclusions: The results show that yeast biofilms can form on the surface of catheters. Candida species are the yeasts which were isolated from these surfaces of infectious patients. C. tropicalis was the most abundant species which was isolated from the patients of this study.
\end{abstract}

Published by Kowsar Corp, 2012. cc 3.0.

- Implication for health policy/practice/research/medical education:

As a medical point of view, the findings can help to detect yeast infections and to control these kinds of infections.

Please cite this paper as:

Mohammadi P, Shoaie N, Roudbar Mohammadi S. Isolation and Detection of Yeast Biofilms From Urine Catheters of Infectious Patients. Jundishapur J Microbiol. 2012;5(4): 533-6. DOI: 10.5812/jjm.2640

\section{Background}

The most important fungal pathogens are yeast species belonging to the genus Candida. Candida species are opportunistic pathogens that can cause superficial mucous membrane infections in life - threatening systemic diseases. Although Candida albicans remains the most frequently cause of Candidiasis, the incidence of the disease caused by non-albicans species has been increased steadily. A major virulence factor of Candida species is its ability to form biofilm. Biofilms are a complex of microorganisms surrounded by a self-production matrix. In fact, biofilms include microbial cells and extra cellular polymeric substances (EPS) $(1,2)$. Biofilms can organize in most types of surfaces such as rocks and industrial line production; some parts of body like teeth and medical devices $(3,4)$. They are responsible for a wide range of infections and mortality especially in hospital infections. In the United States more than 45 million

\footnotetext{
${ }^{*}$ Corresponding author: Parisa Mohammadi, Department of Biology, Faculty of Science, AL Zahra University, Tehran, IR Iran. Tel: +98-2188044051 (2714), Fax: +982188058912,E-mail:p.mohammadi@alzahra.ac.ir

DOI: $10.5812 / j j m .2640$

C 2012 Ahvaz Jundishapur University of Medical Sciences; Published by Kowsar Corp.

This is an Open Access article distributed under the terms of the Creative Commons Attribution License (http://creativecommons.org/licenses/by/3.0), which permits unrestricted use, distribution, and reproduction in any medium, provided the original work is properly cited.
} 
medical implant devices are used every year (5). Relevant Infection to these devices occurs in $1-60 \%$ of patients. It was reported that Candida species cause $20 \%$ of infections. Infections associated with medical devices cause more than $50 \%$ of hospital infections (5). Biofilms exhibit increased resistance against most antimicrobial agents and that is an important problem in treatment of infections related to biofilms (1-6). To treat patients with these kinds of infections, at the first step, it is necessary to identify causes of infection. For this reason, isolation and characterization of yeast from the surface of catheters was carried out.

\section{Objectives}

The aim of this search was to isolate and identify yeasts from the surfaces of urine catheters of infectious patients in ICU award of Army Family Hospital in Tehran. In addition the ability isolated yeasts to form biofilms was also investigated.

\section{Patients and Methods}

In this research, 55 urine catheters from patients of ICU award of Army Family Hospital in Tehran were assayed. The catheters were taken aseptically to the laboratory for studying the biofilms. These catheters were sonicated by sonicator (Elma, Germany) in 60 hertz for 2 minutes. Then cell suspensions were cultured on Sabouraud dextrose agar (Merck, Germany) including $0.05 \mathrm{~g} / \mathrm{L}$ chloram phenicole to eliminate bacterial growth. After that, isolated yeast was cultured on Chrome agar (Himedia), Corn meal agar (Merck). Production of germ tube, assimilation of sugar and PCR method were carried out to identify yeasts at this step. First, yeasts were cultured into sabouraud dextrose broth (Merck, Germany). Next, suspensions of yeasts including $1 \times 10^{6} \mathrm{cells} / \mathrm{ml}$ were transferred into medium containing $(67 \mathrm{gr} / \mathrm{L})$ yeast nitrogen base (Himedia, india) medium including $2 \%$ agar. Then blank disks were submerged on $20 \%$ of sugar solution of glucose, galactose, maltose, lactose, rafinose, terehalose, sucrose, cellobiose and xylose. After that, the disks were placed on the media and production of halo was investigated during 24-48 hours.

For germ tube test, a little of a pure culture of yeast was inoculated to $0.5 \mathrm{ml}$ of human serum and incubated for 2 hour. At 10 minutes intervals, a drop of the yeast-serum mixture was placed on a clean microscope slide, covered by a cover slip and observed through $10 \mathrm{X}$ and $40 \mathrm{X}$ objective lenses of microscope. The appearance of small filaments projecting from the cell surface confirmed formation of germ tubes. The earliest time of each germ tubes production was noted for each serum test (7).

For molecular identification it is necessary to extract DNA of yeasts. Genomic DNA was extracted using the glass bead disruption method. Then PCR was done by a pair of primers ITS1 and ITS4 (Sinagene, Iran). The sequences of the upstream and downstream primers are
5'-TCCGTAGGTGAACCTGCGG 3' (ITS1) and 5'-TCC TCC GCT TAT TGA TAT GC-3' (ITS4), respectively.

PCR amplification was carried out in a final volume of $25 \mu$ l. Each reaction contained $2 \mu$ of template DNA, 12/5 $\mu \mathrm{l}$ master mix, 7/5 $\mu$ l water, $1 / 5 \mu$ l forward primer (ITS1) and $1 / 5 \mu$ reverse primer (ITS 4 ). An initial denaturation step at $94{ }^{\circ} \mathrm{C}$ for 5 min was followed by 34 cycles of denaturation at $94{ }^{\circ} \mathrm{C}$ for $45 \mathrm{~s}$, annealing at $56{ }^{\circ} \mathrm{C}$ for 45 s, extension at $72{ }^{\circ} \mathrm{C}$ for $55 \mathrm{~s}$ and final extension step of $72{ }^{\circ} \mathrm{C}$ for $10 \mathrm{~min}$. Amplified products were visualized by $1 / 5 \%(\mathrm{~W} / \mathrm{V})$ agarose gel electrophoresis in TBE buffer, stained with ethidium bromide and photographed $(8,9)$.

In this study, the MspI enzyme was able to identify and differentiate six species of all yeasts. The reaction mixture and enzyme digestion was prepared as described in Table 1. All tests were performed at room temperature.

Microtubes were incubated for 2 hour at $37{ }^{\circ} \mathrm{C}$. Restriction fragments were separated on $1 / 8 \%$ agarose gel through electrophoresis for $45 \mathrm{~min}$ at $100 \mathrm{~V}$. The gel was stained with ethidium bromide (10).

\begin{tabular}{ll}
\hline Table 1. Component of the MspI Enzyme Digestion Reaction \\
\hline & Components \\
\hline Deionized water & 17 \\
X10Buffer & 2 \\
PCR product & 10 \\
MspI enzyme & 1 \\
\hline Total volume & 30 \\
\hline
\end{tabular}

\section{Results}

55 catheters were collected and assayed in this study. $29 \%$ of organisms which were isolated from urine catheters surface, were yeasts. 10 out of 16 of isolated yeasts were achieved from female patients (\%62.5). It means only 6 yeasts were isolated from male patients (37.5\%).

Glucose, galuctose, maltose and terehalose showed the most amount of absorption and were used by all of yeasts. Among these sugars, lactose and rafinose were quantitavely adsorbed less. Results of culturing on Chromagar, Corn meal agar and germ tube technique was summarized in Table 2. As shown in this table, producing of germ tube and presence of chlamydiospore on Corn meal agar was investigated. The color of colony of C. albicans, C. tropicalis, C. krusei, C. glabrata on chrom agar medium were Clear green, blue - Blue-green, pink and purple, respectively.

Yeast DNA was amplified by ITS1/ITS4 primers. According to molecular techniques, such as DNA extraction, PCR amplification and sequencing of the intragenic transcribed spacers (ITS) the isolated yeasts were identified as Candida albicans, C. tropicalis, C. krusei and C. glabrata. Among 16 yeasts, 4 out of all isolates were identified as C. albicans and 7, 4,1 as a C. tropicalis, C. krusei, and C. glabrata, respectively (Figure). In this study, from catheters of patients, 4 different species of Candida were characterized. 


\begin{tabular}{|lll}
\hline \multicolumn{3}{l}{$\begin{array}{l}\text { Table 2. Results of Producing Germ Tube, Observing of Chlamydospore } \\
\text { on Corn Meal Agar Were Listed in Table. }\end{array}$} \\
\hline & Germ Tube & Corn Meal Agar \\
\hline 1 & + & Producing Chlamydospore \\
\hline 2 & + & Producing Chlamydospore \\
\hline 3 & - & Not producing Chlamydospore \\
\hline 4 & - & Not producing Chlamydospore \\
\hline 5 & - & Not producing Chlamydospore \\
\hline 6 & + & Producing Chlamydospore \\
\hline 7 & - & Not Producing Chlamydospore \\
\hline 8 & - & Not producing Chlamydospore \\
\hline 9 & - & Not producing Chlamydospore \\
\hline 10 & - & Not producing Chlamydospore \\
\hline 11 & - & Not Producing Chlamydospore \\
\hline 12 & + & producing Chlamydospore \\
\hline 13 & - & Not producing Chlamydospore \\
\hline 14 & - & Not producing Chlamydospore \\
\hline 15 & - & Not producing Chlamydospore \\
\hline 16 & - & Not producing Chlamydospore \\
\hline
\end{tabular}

Figure. Patterns of PCR Products of Candida Isolates Before and After Digestion with the Restriction Enzyme MspI.

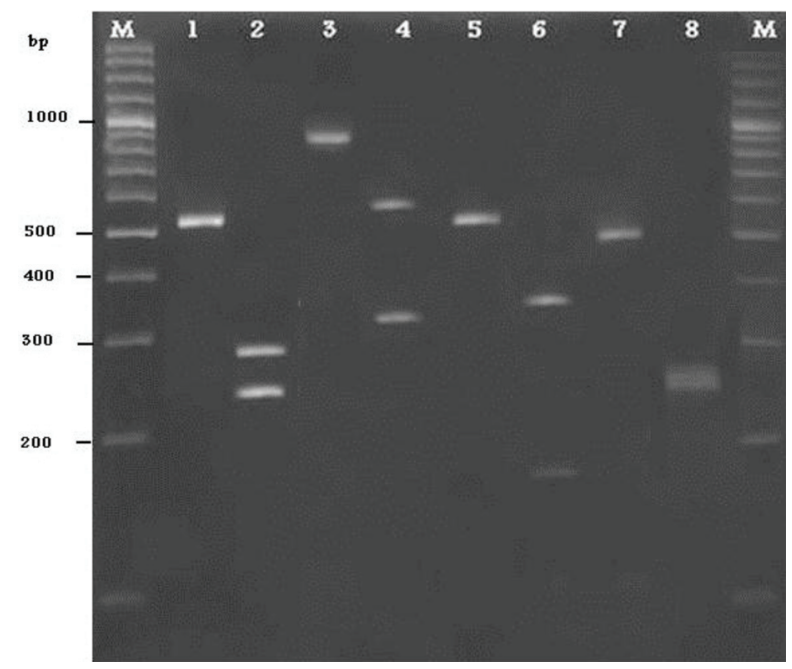

1) PCR product of C.albicans, 2) PCR product of C.albicans after digestion with the restriction enzyme MspI, 3) PCR product of C.glabrata, 4) PCR product of C.glabrata after digestion with the restriction enzyme MspI, 5) PCR product of C.tropicalis, 6) PCR product of C.tropicalis after digestion with the restriction enzyme MspI, 7) PCR product of C.krusei, 8) PCR product of C.tropicalis after digestion with the restriction enzyme MspI.

\section{Discussion}

Candida is a fungus that inhabits in half of oral cavities of human (10). A major virulent factor of Candida species is its ability to adhere and form surface attached microbial communities known as biofilms $(4,10,11)$. Candida biofilms are more resistant than their planktonic counterparts to different antimicrobial agents $(6,11)$. Resistance of Candida biofilms to antifungal agents was first demonstrated in 1995 (2). They have crucial role in causing medical devices infections such as stents, shunts, implants and various types of catheters and hospital infections $(6,11)$. Candida infections of the urinary tract are strongly linked to the presence of urinary catheter (3). In contrast to $13 \%$ of non-catheter associated infections, the National Nosocomial Infections Surveillance (NNIS) data indicated that $C$. albicans caused $21 \%$ of catheter associated urinary tract infections (2). Biomaterials infections are a growing alarming problem because they are highly recalcitrant to antimicrobial therapy (11). Recently studies have shown that many of Candida species are able to attach to polymeric surfaces such as urine catheters and produce biofilms.

In this study abundant of isolated yeast species is $25 \%$ C. albicans, 25\%C. krusei, $6.25 \%$ C. glabrata and $43.75 \%$ C. tropicalis. Molecular techniques and classical methods to identify isolates are in accordance except of some sugar's absorption. RFLP-PCR method is a rapid, easy, and reliable technique. This method can also be used in clinical laboratories to identify clinically important Candida spp. (12). Mirhendi and et al. in 2006 used RFLP-PCR for identifying six medically Candida species (13). Ayatollahi Mousavi et al. identified Candida species isolated from oral colonization in Iranian HIV-positive patients by RFLP-PCR method (14). Furthermore, Mohammadi et al. isolated and identified Candida species in patients with various forms of Candidiasis by using this molecular method. Results of all mentioned researches were accordant with our findings (12).

Febre et al. reported that C. albicans with $46.15 \%$ frequency was the most abundant fungus followed by $C$.glabrata (30.77\%) and C. krusei (7.7\%) from urine specimens (15). These results indicated that C. tropicalis has been replaced with C. albicans and C. tropicalis has the major role to cause yeast infections in form of biofilm. Also in other studies the presence of yeasts in $18.6 \%$ of urine specimens of patients with indwelling urinary catheters were observed (15). The results of this study revealed the presence of yeasts in $32 \%$ of patients with urinary catheters which indicates the fungal infections 'increasing. Pakshir was shown in patients with urine catheters involving both bacterial and Candida infections with abundance of $50.4 \%$ and $28.7 \%$, respectively (16). Febre et al. have reported, women in comparison to men, are more susceptible to expose yeast infections (15). Pakshir has reported that abundance of Candidiasis in women and men was $68.9 \%$ and $31.1 \%$, respectively (16). These findings are in accordance with our results. It can be concluded that yeast infections were increased in recent years and the crucial problem of this fungal structure is their resistant to antimicrobial agents because of biofilm formation. Further investigation will be carried out to assay antibiofilm agents against Candida species isolated from surface of urine catheters.

\section{Acknowledgments}

This study was financially supported by vice chancellor 
for research of Alzahra University. We are grateful of medical mycology group for providing laboratory facilities. The authors extend their thanks to Rahmani and Family Army Hospital technicians for their assistance to collect catheters of patients.

\section{Financial Disclosure}

Parisa Mohammadi was financially supported by Alzahra University Tehran, IR Iran.

\section{Funding Support}

The study supported by Alzahra University, Tehran, IR Iran.

\section{References}

1. Ferreira JA, Carr JH, Starling CE, de Resende MA, Donlan RM. Bioo film formation and effect of caspofungin on biofilm structure of Candida species bloodstream isolates. Antimicrob Agents Chemother. 2009;53 (10):4377-84.

2. Kokare C, Chakraborty S, Khopade A, Mahadik K. Biofilm: Importance and applications. Indian J Biotechnol. 2009;8 (2):159-68.

3. Dominic RM, Shenoy S, Baliga S. Candida biofilms in medical devices: evolving trends. Kathmandu Univ Med J (KUMJ). 2007;5 (3):431-6.

4. Pusateri CR, Monaco EA, Edgerton M. Sensitivity of Candida albicans biofilm cells grown on denture acrylic to antifungal proteins and chlorhexidine. Arch Oral Biol. 2009;54 (6):588-94.

5. Nett J, Andes D. Candida albicans biofilm development, modeling a host-pathogen interaction. Curr Opin Microbiol. 2006;9 (4):340-5.

6. Suci PA, Tyler BJ. A method for discrimination of subpopulations of Candida albicans biofilm cells that exhibit relative levels of phenotypic resistance to chlorhexidine. J Microbiol Methods. 2003;53 (3):313-25.
7. Isibor JO, Eghubare AE, Omoregie R. Germ Tube Formation in Candida Albicans:Evaluation of Human and Animal Sera and Incubation Atmosphere. Shiraz E-Med J. 2005;6 (1).

8. Mirhendi SH, Kordbacheh P, Pezeshki M, Khorramizadeh MR. Simple and rapid identification of most medically important Candida species by a PCR-restriction enzyme method. Acta Medica Iranica. 2003;41 (2).

9. Yamada Y, Makimura K, Merhendi H, Ueda K, Nishiyama Y, Yamaguchi $\mathrm{H}$, et al. Comparison of different methods for extraction of mitochondrial DNA from human pathogenic yeasts. Jpn J Infect Dis. 2002;55(4):122-5.

10. da Silva WJ, Seneviratne J, Parahitiyawa N, Rosa EA, Samaranayake LP, Del Bel Cury AA. Improvement of XTT assay performance for studies involving Candida albicans biofilms. Braz Dent J. 2008;19 (4):364-9.

11. Ramage G, Martinez JP, Lopez-Ribot JL. Candida biofilms on im planted biomaterials: a clinically significant problem. FEMS Yeas Res. 2006;6 (7):979-86.

12. Mohammadi R, Mirhendi H, Yadegari MH, Shadzi S, Jalalizand N. Identification and frequency of Candida species in patients with different forms of Candidiasis in Isfahan, using PCR-RFLP method. JIMS. 2011;29 (133).

13. Mirhendi H, Makimura K, Khoramizadeh M, Yamaguchi H. A one-enzyme PCR-RFLP assay for identification of six medically important Candida species. Nihon Ishinkin Gakkai Zasshi. 2006;47 (3):225-9.

14. Ayatollahi Mousavi SA, Salari S, Rezaie S, Shahabi Nejad N, Hadizadeh S, Kamyabi $\mathrm{H}$, et al. Identification of Candida Species Isolated from Oral Colonization in Iranian HIV-Positive Patients, by PCR-RFLP Method. Jundishapur J Microbiol. 2012;5 (1).

15. Febre N, Silva V, Medeiros EA, Wey SB, Colombo AL, Fischman O. Microbiological characteristics of yeasts isolated from urinary tracts of intensive care unit patients undergoing urinary catheterization. J Clin Microbiol. 1999;37 (5):1584-6.

16. Pakshir K. Evolution Candidasis and urinary tract infection caused by the use of urinary catheters [Thesis]. Tehran: Tehran Medical University; 1996. 